\section{Assessment of endothelial} function: comparison of the pulse wave response to $\beta_{2}$-adrenoceptor stimulation

\section{with flow}

Curtis Rambaran, Benyu Jiang, James M. Ritter, Ajay Shah, Lalit Kalra \& Philip J. Chowienczyk

Cardiovascular Division, King's College London School of Medicine, London

\section{Correspondence}

Dr P. J. Chowienczyk, Department of Clinical Pharmacology, St Thomas' Hospital, London, SE1 7EH, UK. E-mail: phil.chowienczyck@kcl.ac.uk

\section{Keywords}

endothelial function, beta-androceptor, pulse wave analysis, flow mediated dilatation

\section{Received}

22 January 2007

Accepted

12 June 2007

Published OnlineEarly 22 October 2007

\title{
AIMS
}

To assess the reproducibility of the digital pulse wave response to $\beta_{2}$-adrenoreceptor stimulation and to determine if an attenuated response to $\beta_{2}$-adrenoceptor stimulation is associated with impaired flow mediated dilatation (FMD).

\section{METHODS}

Subjects $(n=20)$ with endothelial dysfunction (ED), were compared with healthy control subjects $(n=20)$. Change in reflection index

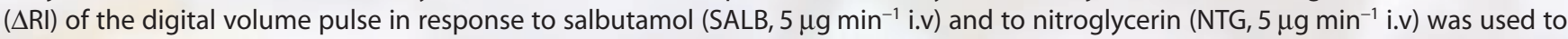
assess endothelium-dependent $\left(\Delta \mathrm{RI}_{\mathrm{SALB}}\right)$ and endothelium-independent $\left(\Delta \mathrm{RI}_{\mathrm{NTG}}\right)$ pressure wave reflection. $\Delta \mathrm{RI}_{\mathrm{SALB}}$ was assessed on two occasions to examine reproducibility. High resolution ultrasound of the brachial artery was used to measure FMD and also dilation to NTG (NTGD).

\section{RESULTS}

The mean difference in $\Delta \mathrm{RI}_{\text {SALB }}$ between two visits was $-0.2 \%$, with SD of the difference $4.9 \%$. Both $\Delta \mathrm{RI}_{\mathrm{SALB}}$ and FMD were impaired in subjects with ED compared with values in control subjects $(5.0 \pm 0.7$ vs. $11.3 \pm 1.2 \%$, mean values \pm SEM, $P<0.01$ and $4.2 \pm 0.6$ vs. $7.5 \pm 0.8 \%, P<0.02$ for $\Delta \mathrm{RI}_{\mathrm{SALB}}$ and $\mathrm{FMD}$, respectively), whereas $\Delta \mathrm{RI}_{\mathrm{NTG}}$ and NTGD were similar in the two groups. $\Delta \mathrm{RI} \mathrm{IALB}_{\mathrm{B}}$ was correlated with FMD $(r=0.44, P<0.01)$ and had $88 \%$ sensitivity and $79 \%$ specificity to detect abnormal (FMD $<4 \%)$.

\section{CONCLUSIONS}

The pulse wave response to a $\beta_{2}$-adrenoceptor agonist correlates with FMD and has high sensitivity and specificity in detecting abnormal endothelial function as defined by FMD. However, FMD is the preferred test to detect effects of interventions on endothelial function.

\section{Introduction}

Endothelial function in vivo in man is usually assessed by examining the vasodilator response to an endotheliumdependent stimulus, such as intra-arterial administration of acetylcholine (ACh) $[1,2]$ or an increase in blood flow and hence in shear stress. Shear stress stimulates the endothelium to release nitric oxide (NO) with subsequent vasodilation that can be imaged and quantified as an index of vasomotor function. Dilatation of the brachial artery to an increase in flow (flow mediated dilatation, FMD) during reactive hyperaemia following restoration of blood flow after a period of ischaemia in the hand is the current 'gold standard' for noninvasive assessment of endothelial function [3]. This technique, however, requires specialist imaging equipment and great attention to detail in order to obtain reproducible results [4].

We and others have suggested an alternative approach to assessing endothelial function, measuring the vasodilator response to $\beta_{2}$-adrenoceptor agonists [5-7].Vasodilator 


\section{Table 1}

Subject characteristics

\begin{tabular}{|c|c|c|}
\hline & $\begin{array}{l}\text { Endothelial dysfunction } \\
(n=20)\end{array}$ & $\begin{array}{l}\text { Control subjects } \\
(n=20)\end{array}$ \\
\hline Age (years) & $46.7(9.8)^{*}$ & $41.1(8.6)$ \\
\hline Sex (M/F) & $11 / 9$ & $11 / 9$ \\
\hline Height (m) & $1.66(0.11)$ & $1.71(0.11)$ \\
\hline Weight (kg) & $80.9(13.5)^{*}$ & $71.7(11.8)$ \\
\hline BMI $\left(\mathrm{kg} \mathrm{m}^{-2}\right)$ & $29.2(5.2)^{*}$ & $24.2(2.6)$ \\
\hline Smoker/nonsmoker & $2 / 20$ & $3 / 20$ \\
\hline Systolic BP (mmHg) & $146.5(21.3)^{* *}$ & $118.1(9.1)$ \\
\hline Diastolic BP $(\mathrm{mmHg})$ & $92.5(11.7)^{\star *}$ & $72.5(7.2)$ \\
\hline Total-cholesterol $\left(\mathrm{mmol} \mathrm{I}^{-1}\right)$ & $5.0(0.9)$ & $4.7(0.9)$ \\
\hline HDL-cholesterol $\left(\mathrm{mmol} \mathrm{I}^{-1}\right)$ & $1.6(0.5)$ & $1.8(0.6)$ \\
\hline LDL-cholesterol $\left(\mathrm{mmol} \mathrm{I}^{-1}\right)$ & $2.8(0.8)$ & $2.4(0.8)$ \\
\hline Triglycerides $\left(\mathrm{mmol} \mathrm{I}^{-1}\right)$ & $1.1(0.7)$ & $1.1(0.6)$ \\
\hline Glucose (mmol/l) & $4.1(0.9)$ & $4.5(0.8)$ \\
\hline Diuretics (\%) & 7 (35) & \\
\hline$\alpha$-adrenoceptor blockers (\%) & $5(25)$ & \\
\hline
\end{tabular}

Values are means (SD) or numbers (\%). ${ }^{*} \mathrm{P}<0.05,{ }^{*} \mathrm{P}<0.01$ compared with control subjects.

responses to $\beta_{2}$-adrenoceptor agonists are mediated in part by endothelium-derived NO $[7,8]$. Low doses of salbutamol (SALB), a selective $\beta_{2}$-adrenoceptor agonist, have minimal effects on blood pressure but influence the arterial pulse waveform [5]. SALB reduces reflection index (RI) [5] of the digital volume pulse and augmentation index of the radial pressure pulse [6] as a result of vasodilation of muscular arteries proximal to resistance vessels but distal to conduit vessels. Using this technique we have demonstrated reduced vasodilator responsiveness to $\beta_{2}$-adrenoceptor stimulation in association with essential hypertension/ metabolic syndrome and ethnic differences in vascular responsiveness between Afro-Caribbeans and Caucasians $[9,10]$. However, because the pulse wave response to $\beta_{2}$-adrenoceptor stimulation involves a different mechanism in activating NO mediated vasodilation from that for FMD and is assessed in a different vascular bed (systemic arteries vs. forearm conduit arteries) it is unknown whether an abnormal pulse wave response to $\beta_{2}$-adrenoceptor stimulation is associated with impaired FMD.

The purpose of this present study was 1) to assess the reproducibility of the pulse wave response to $\beta_{2^{-}}$ adrenoceptor stimulation and 2) to determine if an attenuated response to $\beta_{2}$-adrenoceptor stimulation is associated with impaired FMD. We studied a group of subjects with risk factors in whom our previous work had identified impaired $\beta_{2}$-adrenoceptor responses (endothelial dysfunction, ED group) and a group of healthy control subjects.

\section{Methods}

\section{Subjects}

Subjects with risk factors and hence assumed to have ED were recruited from the Vascular Risk Clinic at King's
College Hospital, London. The majority of subjects were overweight/obese hypertensives and included treated hypertensives. Subjects treated with $\beta$-adrenoceptor blocking agents and drugs known to modify endothelial function: aspirin [11], statins [12], angiotensin converting enzyme inhibitors [13], angiotensin II receptor antagonists [14] and calcium channel antagonists [15] were excluded. Healthy normotensive volunteers were recruited by advertisement within the local community. The study was approved by King's College Hospital Research Ethics Committee and informed consent was obtained from each participant. Subject characteristics are summarized in Table 1.

\section{DVP response to SALB and nitroglycerin and reproducibility of response to $S A L B$}

The digital volume pulse (DVP) was recorded using an infrared photoplethysmograph (Micro Medical, Gillingham, UK) placed on the index finger of the left hand. This was used to assess the response to SALB and nitroglycerin (NTG, an endothelium-independent NO donor) [5].In order to avoid confounding effects due to variable absorption or first pass metabolism, SALB and NTG were administered by the intravenous route as previously described [10]. The response to SALB was repeated after 1 week in order to determine its reproducibility. All studies were performed in a temperature controlled $\left(24 \pm 1^{\circ} \mathrm{C}\right)$ vascular laboratory in the morning with subjects having fasted overnight and having avoided caffeine and alcohol containing beverages from the evening before. Following venous cannulation, subjects rested supine for $30 \mathrm{~min}$. Baseline measurements of blood pressure (using an Omron 705CP oscillometric device, Omron, Japan) and DVP were obtained at $5 \mathrm{~min}$ intervals for $15 \mathrm{~min}$. SALB (5 $\mu \mathrm{g} \mathrm{min}^{-1}$, Allen \& Hanbury, UK) was then infused for 30 min during which haemodynamic 
measurements were recorded at $3 \mathrm{~min}$ intervals. After a washout period of 60 min during which $0.9 \%$ sodium chloride was infused, all parameters returned to baseline. NTG $\left(5 \mu \mathrm{g} \mathrm{min}^{-1}\right.$, Faulding, UK) was then infused for $30 \mathrm{~min}$ with haemodynamic measurements recorded at 3 min intervals. The response to SALB was assessed in an identical manner on a second occasion, 1 week after the first pulse wave study.

\section{Flow mediated dilatation (FMD)}

FMD was measured in the morning after an overnight fast within 1 week of pulse wave studies and under identical conditions according to current guidelines [4]. A high resolution ultrasound (Accuson 128XP/10) system with $7 \mathrm{MHz}$ linear array transducer, positioned by a stereotactic manipulator) was used to scan the brachial artery in a longitudinal section $2-15 \mathrm{~cm}$ above the elbow. After optimal positioning of the transducer a baseline scan was recorded. Increased flow was then induced by inflation of a pneumatic tourniquet placed around the forearm (distal to the arterial segment being scanned) to a pressure of $250 \mathrm{mmHg}$ for $5 \mathrm{~min}$, followed by release. A second scan commenced $10 \mathrm{~s}$ before release of the cuff and continued for $3 \mathrm{~min}$ after cuff deflation. After $10 \mathrm{~min}$ to allow vessel recovery, another resting scan was taken. Sublingual GTN $(500 \mu \mathrm{g})$ was then administered, and a final scan performed 3-4 min later. Images were coded and recorded on VHS videotape, then digitized for subsequent blinded analysis using automated edge detection software (Brachial Analyser, Medical Imaging Applications, LCC, lowa, USA). FMD was expressed as the percentage increase in brachial artery diameter from baseline to maximal dilation which occurred 30-90 s after release of the cuff. Dilation to NTG (NTGD) was expressed as the percentage increase in brachial artery diameter from baseline to maximal dilation after NTG.

\section{Statistical analysis}

Subject characteristics are expressed as means (SD) and results as means \pm SEM. Change in $\mathrm{Rl}$ in response to SALB $\left(\Delta R \mathrm{I}_{\text {SALB }}\right)$, was quantified by measuring the change from baseline (mean of values recorded at 15, 10,5 and 0 min before the start of the infusion of SALB), during the period 12-21 min after the start of infusion [10], expressed as a percentage of the baseline value. $\Delta \mathrm{RI}_{\text {SALB }}$ was compared in the two groups by Student's $t$-test (two-tailed), $P<0.05$ was considered significant. Reproducibility of $\Delta \mathrm{RI}_{\mathrm{SALB}}$ was investigated using a Bland-Altman plot [16] and expressed in terms of the mean difference of $\Delta \mathrm{RI}_{\text {SALB }}$ for the two visits and SD of this difference. The correlation between $\Delta \mathrm{RI}_{\text {SALB }}$ (mean value for both visits) and FMD was examined by linear regression analysis using Pearson's test of correlation. Previous studies using FMD have shown that in healthy people FMD is $7-10 \%$ of the baseline diameter but in patients with cardiovascular disease, FMD is impaired or absent with $\mathrm{FMD}<5 \%$ [17]. We used cut off values of
FMD $>8 \%$ as indicative of normal endothelial function and FMD $<4 \%$ as abnormal endothelial function [18]. The sensitivity and specificity of $\Delta \mathrm{RI}$ to detect normal and abnormal endothelial function according to this definition was determined using a receiver operating characteristic (ROC) plot.

\section{Results}

Subject characteristics are summarized in Table 1. Subjects with ED had higher blood pressure, weight and higher BMI than control subjects. Values of Rl at baseline were similar in subjects with ED compared with control subjects $(77.0 \pm 1.5$ vs. $76.0 \pm 3.4 \%, P=\mathrm{NS})$, a finding consistent with that in other studies [10]. There was no significant difference in baseline brachial artery diameter between the groups ( $4.1 \pm 0.9$ in controls vs. $3.9 \pm 0.6 \mathrm{~mm}$ in ED subjects, $P=\mathrm{NS}$ ).

\section{Reproducibility of DVP response to SALB}

Baseline values and haemodynamic changes in response to SALB on the 2 study days were similar.The Bland-Altman plot for $\Delta \mathrm{Rl}_{\text {SALB }}$ determined on two occasions separated by 1 week is shown in Figure 1. There was no relation between the difference in paired measurements and the size of $\Delta \mathrm{RI}_{\text {SALB }}$ (no trend for within subject variability to be dependent on the mean value of $\Delta \mathrm{RI}_{\text {SALB }}$ ). The mean difference in $\Delta \mathrm{RI}_{\text {SALB }}$ between the two visits was $-0.2 \%$ with SD of this difference $4.9 \%$.

\section{Comparison of pulse wave response and FMD in ED and control subjects}

Haemodynamic changes in response to SALB and NTG are summarized in Table 2 . In ED subjects, both $\Delta \mathrm{RI}_{\text {SALB }}$ and FMD were impaired compared with values in control subjects $(5.0 \pm 0.7$ vs. $11.3 \pm 1.2 \%, P<0.01$ and $4.2 \pm 0.6$ vs. $7.5 \pm 0.8 \%, P<0.02$ for $\Delta \mathrm{RI}_{\mathrm{SALB}}$ and $\mathrm{FMD}$, respectively, Figure 2). $\triangle \mathrm{R} \mathrm{I}_{\mathrm{NTG}}$ and NTGD were preserved in ED compared to control subjects $(12.6 \pm 0.7$ vs. $15.1 \pm 1.1 \%, P=0.25$ and $16.4 \pm 0.8$ vs. $15.7 \pm 0.8 \%, P=0.45$ for $\Delta \mathrm{RI}_{\mathrm{NTG}}$ and NTGD, respectively). In all subjects there was a significant correlation between $\Delta \mathrm{RI}_{\text {SALB }}$ and FMD $(r=0.44, P<0.01) . \Delta \mathrm{RI}_{\mathrm{NTG}}$ and NTGD were not significantly correlated. Using a cut-off value of $8 \%$ for $\triangle \mathrm{RI}_{\mathrm{ALB}}$, the DVP response to SALB had $88 \%$ sensitivity and $79 \%$ specificity to detect abnormal endothelial function (as defined by FMD $<4 \%$ ). The ROC plot is shown in Figure 3.

\section{Discussion}

The pulse wave response to SALB is a simple test which does not require specialized equipment or training and can be used in studies with more than one centre [10]. In the present study we assessed the correlation of $\Delta \mathrm{RI}_{\text {SALB }}$ 


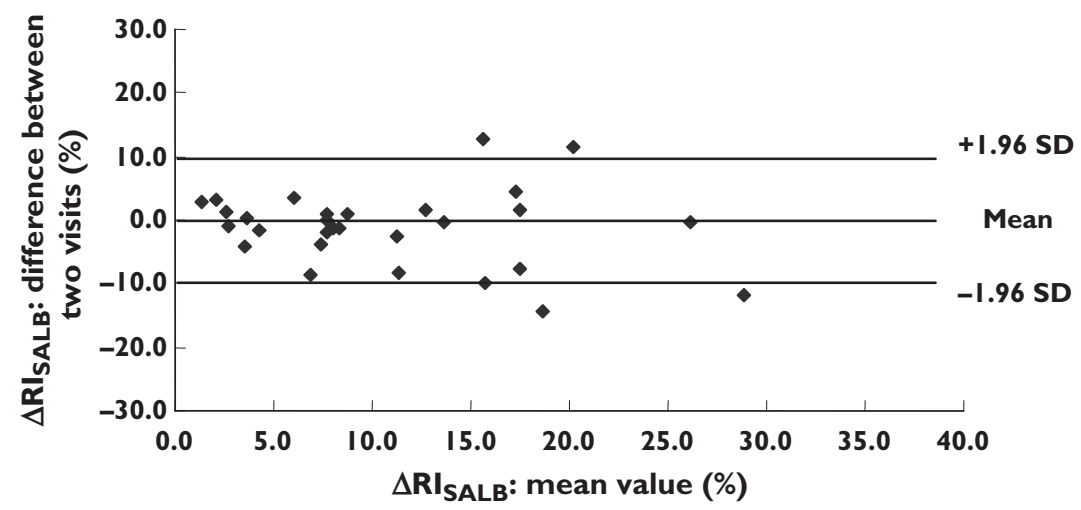

\section{Figure 1}

Bland-Altman plot showing the difference in response of the reflection index of the digital volume pulse to salbutamol $\left(\Delta \mathrm{RI}_{\mathrm{SALB}}\right)$ measured on two occasions $v s$. the mean value for the two occasions

\section{Table 2}

Haemodynamic and digital pulse parameters at baseline and during intravenous infusion of salbutamol (SALB) and nitroglycerin (NTG)

\begin{tabular}{|c|c|c|c|c|c|c|}
\hline & \multicolumn{3}{|c|}{ Control subjects } & \multicolumn{3}{|c|}{ Endothelial dysfunction } \\
\hline & Baseline & $\begin{array}{l}\text { SALB } \\
\left(5 \mu \mathrm{g} \min ^{-1}\right)\end{array}$ & $\begin{array}{l}\text { NTG } \\
\left(5 \mu \mathrm{g} \min ^{-1}\right)\end{array}$ & Baseline & 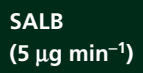 & $\begin{array}{l}\text { NTG } \\
\left(5 \mu \mathrm{g} \mathrm{min}{ }^{-1}\right)\end{array}$ \\
\hline SBP $(\mathrm{mmHg})$ & $117 \pm 2$ & $119 \pm 3$ & $119 \pm 3$ & $148 \pm 4$ & $148 \pm 3$ & $143 \pm 4$ \\
\hline DBP $(m m H g)$ & $74 \pm 2$ & $69 \pm 3$ & $70 \pm 2$ & $93 \pm 3$ & $86 \pm 3$ & $86 \pm 3$ \\
\hline RI (\%) & $77.3 \pm 1.5$ & $66.0 \pm 3.1$ & $62.2 \pm 3.3$ & $76.4 \pm 3.4$ & $71.4 \pm 3.4$ & $63.8 \pm 2.2$ \\
\hline$\Delta \mathrm{RI}(\%)$ & & $11.3 \pm 1.2$ & $15.1 \pm 1.1$ & & $5.0 \pm 0.7$ & $12.6 \pm 0.7$ \\
\hline
\end{tabular}

Values are means \pm SEM; BP: blood pressure; RI: reflection index of the digital volume pulse.

with FMD and the reproducibility of $\triangle \mathrm{RI}_{\mathrm{SALB}}$. The correlation between $\Delta \mathrm{RI}_{\text {SALB }}$ and FMD was significant but relatively low. This may be because the measurements are in different vascular beds and activated by different mechanisms. It is notable that the correlation of forearm blood flow methods for measuring endothelial function with FMD has also been reported to be weak [19].

The within-subject standard deviation of $\Delta \mathrm{RI}_{\text {SALB }}$ for successive visits is determined by the physiological variability in vascular reactivity and by the intrinsic error in the test. The within subject $\mathrm{SD}$ for $\Delta \mathrm{RI}_{\text {SALB }}$ was $4.9 \%$, slightly less than the difference in $\triangle \mathrm{RI}_{\mathrm{SALB}}$ between the $\mathrm{ED}$ and control groups in this study. This degree of variability means that a relatively large sample size would be required to detect a modest change in $\triangle \mathrm{RI}_{\text {SALB }}$ (i.e. a change substantially less than the difference in $\Delta \mathrm{RI}_{\text {SALB }}$ between the ED and control groups in this study). The ratio of the within subject SD to the difference between the ED and control subjects for $\Delta \mathrm{RI}_{\text {SALB }}$ in this study was 0.8 which compares with a ratio of approximately 0.5 for FMD (assuming a within subject SD for FMD of approximately 1.5\%). Thus the pulse wave technique is substantially less powerful than FMD in detecting a within-subject change in endothelial function. A similar conclusion was reached by Donald et al. [20] when comparing the reproducibility of the salbutamol response assessed by pulse wave analysis (using both the digital pulse and radial tonometry) in children and adults.

The power of a test to discriminate between two groups with differing endothelial function depends upon the SD of the test in each group and the size of the difference between the groups. Variation in vascular function between subjects is likely to play a more important role in determining within group SD, and thus the intrinsic error of the test may be of less importance when comparing differences between groups. In the present study the ratios of the within group SD to the between group difference were 1.3 and 1.0 for $\Delta \mathrm{RI}_{\text {SALB }}$ and FMD respectively, so the difference in power of the two tests to detect differences in endothelial function between groups was less marked than that to detect a within-subject change but still favored FMD. The ROC analysis we performed suggests that the pulse wave response to SALB has adequate sensitivity and specificity in determining the presence of endothelial dysfunction as determined by FMD. A limitation of 
a

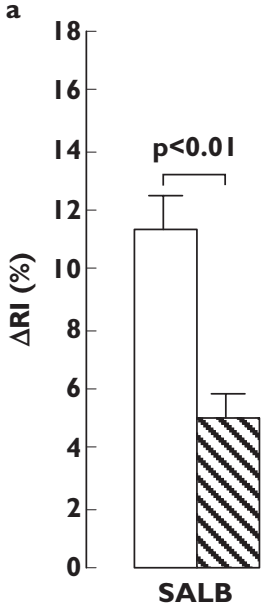

b

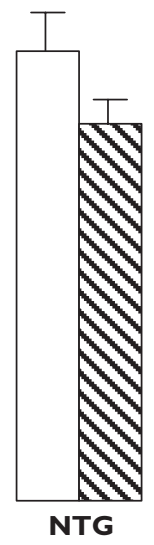

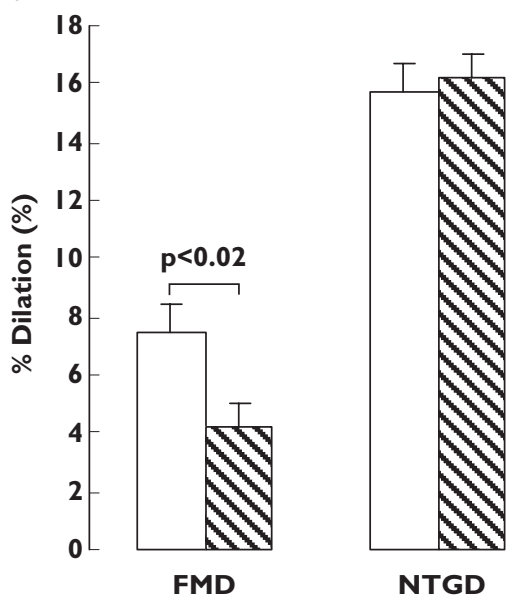

\section{Figure 2}

(a) Response of the reflection index ( $\triangle \mathrm{RI}$ ) of the digital volume pulse to salbutamol (SALB) and nitroglycerin (NTG) in subjects with endothelial dysfunction and control subjects. (b) Dilation of the brachial artery to hyperaemic flow (FMD) and to NTG in the same subject groups. Endothelial dysfunction, ( $\mathbb{B})$; Control subjects, $(\square)$

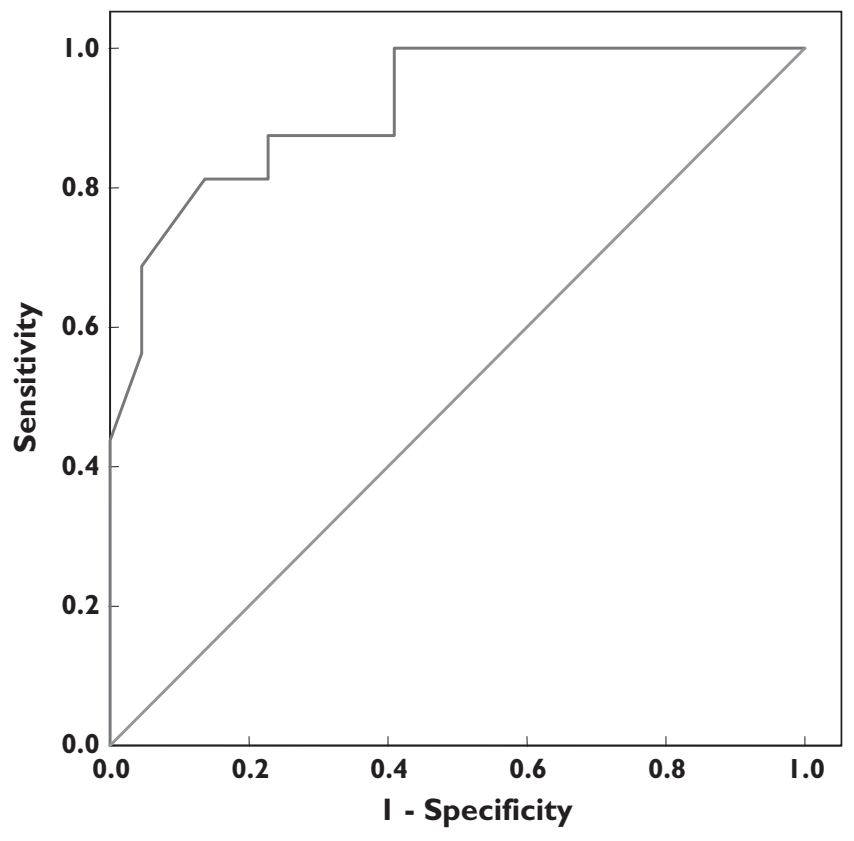

Figure 3

ROC curve for the pulse wave response to salbutamol $\left(\Delta \mathrm{RI}_{\mathrm{SALB}}\right)$ as a predictor of abnormal FMD (<4\%). Sensitivity equals the number of subjects with abnormal FMD and abnormal $\triangle \mathrm{Rl}_{\text {SALB }}$ divided by the total number of subjects with abnormal FMD. Specificity equals the number of subjects with normal FMD and normal $\triangle \mathrm{RI}_{\text {SALB }}$ divided by total number of subjects with normal FMD. The area under the curve (AUC: $0.92,95 \% \mathrm{Cl} 0.83,1.00$ ) is close to 1 and suggests that the discriminatory value of $\Delta \mathrm{RI}_{\mathrm{SALB}}$ in the detection of abnormal endothelial function as defined by FMD is satisfactory the present study is that the relationship between $\Delta \mathrm{RI}$, NTGD and FMD may depend in part on the doses of salbutamol and NTG used for the two tests. The doses used for the pulse wave response were chosen to produce a change in Rl with minimum systemic effects but we cannot exclude the possibility that the sensitivity and specificity might be improved by altering these doses.

In conclusion, the digital pulse wave response to SALB correlates with FMD and is broadly similar in identifying subjects with endothelial dysfunction. However, the within subject variation of the pulse wave response is greater than FMD and thus, where available, FMD is the preferred test to detect effects of interventions on endothelial function.

\section{REFERENCES}

1 Furchgott RF, Zawadzki JV. The obligatory role of endothelial cells in the relaxation of arterial smooth muscle by acetylcholine. Nature 1980; 288: 373-6.

2 Ludmer PL, Selwyn AP, Shook TL, Wayne RR, Mudge GH, Alexander RW, Ganz P. Paradoxical vasoconstriction induced by acetylcholine in atherosclerotic coronary arteries. $\mathrm{N}$ Engl J Med 1986; 315: 1046-51.

3 Celermajer DS, Sorensen KE, Gooch VM, Spiegelhalter DJ, Miller OI, Sullivan IDL, Loyd JK, Deanfield JE. Non-invasive detection of endothelial dysfunction in children and adults at risk of atherosclerosis. Lancet 1992; 340: 1111-5.

4 Corretti MC, Anderson TJ, Benjamin EJ, Celermajer D, Charbonneau F, Creager MA, Deanfield J, Drexler H, 
Gerhard-Herman M, Herrington D, Vallance P, Vita J, Vogel R. Guidelines for the ultrasound assessment of endothelial-dependent flow-mediated vasodilation of the brachial artery: a report of the International Brachial Artery Reactivity Task Force. J Am Coll Cardiol 2002; 39: 257-65.

5 Chowienczyk PJ, Kelly RP, MacCallum H, Millasseau SC, Andersson TL, Gosling RG, Ritter JM, Anggard EE. Photoplethysmographic assessment of pulse wave reflection: blunted endothelium-dependent response to beta ${ }_{2}$ adrenergic vasodilation in type II diabetes. J Am Coll Cardiol 1999; 34: 2007-14.

6 Hayward CS, Kraidly M, Webb CM, Collins P. Assessment of endothelial function using peripheral waveform analysis: a clinical application. J Am Coll Cardiol 2002; 40: 521-8.

7 Wilkinson IB, Hall IR, MacCallum H, Mackenzie IS, McEniery CM, van der Arend BJ, Shu YE, Mackay LS, Webb DJ, Cockcroft JR. Pulse-wave analysis: clinical evaluation of a noninvasive, widely applicable method for assessing endothelial function. Arterioscler Thromb Vasc Biol 2002; 22: 147-52.

8 Dawes M, Chowienczyk PJ, Ritter JM. Effects of inhibition of the 1-arginine/nitric oxide pathway on vasodilation caused by beta-adrenergic agonists in human forearm. Circulation 1997; 95: 2293-7.

9 Kalra L, Rambaran C, Chowienczyk P, Goss D, Hambleton I, Ritter J, Shah A, Wilks R, Forrester T. Ethnic differences in arterial responses and inflammatory markers in Afro-Caribbean and Caucasian subjects. Arterioscler Thromb Vasc Biol 2005; 25: 2362-7.

10 Kalra L, Rambaran C, Iveson E, Chowienczyk PJ, Hambleton I, Ritter JM, Shah A, Wilks R, Forrester T. The role of inheritance and environment in predisposition to vascular disease in people of African descent. J Am Coll Cardiol 2006; 47: 1126-33.

11 Husain S, Andrews NP, Mulcahy D, Panza JA, Quyyumi AA. Aspirin improves endothelial dysfunction in atherosclerosis. Circulation 1998; 97: 716-20.

12 Mason RP, Walter MF, Jacob RF. Effects of HMG-CoA reductase inhibitors on endothelial function: role of microdomains and oxidative stress. Circulation 2004; 109 : 1134-41.

13 Keelan PC, Prasad A, Barsness GW. Improving endothelial function with ACE inhibitors: An important therapeutic target after coronary interventions. Curr Interv Cardiol Report 2001; 3: 244-50.

14 Higashi Y, Chayama K, Yoshizumi M. Angiotensin II type I receptor blocker and endothelial function in humans. role of nitric oxide and oxidative stress. Curr Med Chem Cardiovasc Hematol Agents 2005; 3: 133-48.

15 Verhaar MC, Honing ML, van Dam T, Zwart M, Koomans HA, Kastelein JJ, Rabelink TJ. Nifedipine improves endothelial function in hypercholesterolemia, independently of an effect on blood pressure or plasma lipids. Cardiovasc Res 1999; 42: 752-60.

16 Bland JM, Altman DG. Statistical methods for assessing agreement between two methods of clinical measurement. Lancet 1986; 1: 307-10.

17 Moens AL, Goovaerts I, Claeys MJ, Vrints CJ. Flow-mediated vasodilation: a diagnostic instrument, or an experimental tool? Chest 2005; 127: 2254-63.

18 Schroeder S, Enderle MD, Ossen R, Meisner C, Baumbach A, Pfohl M, Herdeg C, Oberhoff M, Haering HU, Karsch KR. Noninvasive determination of endothelium-mediated vasodilation as a screening test for coronary artery disease: pilot study to assess the predictive value in comparison with angina pectoris, exercise electrocardiography, and myocardial perfusion imaging. Am Heart J 1999; 138 : 731-9.

19 Lind L, Fors N, Hall J, Marttala K, Stenborg A. A comparison of three different methods to evaluate endothelium-dependent vasodilation in the elderly: the Prospective Investigation of the Vasculature in Uppsala Seniors (PIVUS) study. Arterioscler Thromb Vasc Biol 2005; 25: $2368-75$.

20 Donald AE, Charakida M, Cole TJ, Friberg P, Chowienczyk PJ, Millasseau SC, Deanfield JE, Halcox JP. Non-invasive assessment of endothelial function: which technique? J Am Coll Cardiol 2006; 48: 1846-50. 